Published in final edited form as:

Exp Hematol. 2015 August ; 43(8): 732-741. doi:10.1016/j.exphem.2015.04.010.

\title{
Novel therapeutic strategies for multiple myeloma
}

\author{
Naoya Mimura ${ }^{1}$, Teru Hideshima ${ }^{2}$, and Kenneth C. Anderson ${ }^{2}$ \\ ${ }^{1}$ Department of Transfusion Medicine and Cell Therapy, Chiba University Hospital, Chiba, Japan \\ 2Jerome Lipper Multiple Myeloma Center, Department of Medical Oncology, Dana-Farber Cancer \\ Institute, Harvard Medical School, Boston, MA, USA
}

\begin{abstract}
Multiple Myeloma (MM) is a plasma cell malignancy which remains incurable despite of the recent emergence of multiple novel agents. Importantly, recent genetic and molecular analyses have revealed the complexity and heterogeneity of this disease, highlighting the need for therapeutic strategies to eliminate all the clones. Moreover, the bone marrow microenvironment, including stromal cells and immune cells, plays a central role in MM pathogenesis, promoting tumor cell growth, survival, and drug resistance. New classes of agents including proteasome inhibitors, immunomodulatory drugs, monoclonal antibodies, and histone deacetylase inhibitors have shown remarkable efficacy; however, novel therapeutic approaches are still urgently needed to further improve patient outcome. In this review, we discuss the recent advances and future strategies to ultimately develop MM therapies with curative potential.
\end{abstract}

\section{Introduction}

\begin{abstract}
Multiple myeloma (MM) is characterized by the clonal proliferation of malignant plasma cells in the bone marrow (BM), lytic bone lesions, and immunodeficiency, associated with monoclonal protein in the blood and/or urine. It accounts for $1 \%$ of all cancers and more than $10 \%$ of all hematological malignancies. In spite of recent advances in treatment including high-dose therapy and novel agents such as bortezomib, thalidomide, and lenalidomide, MM remains fatal due to development of drug resistance in the context of BM microenvironment [1-4]. To overcome this drug resistance, a number of therapeutic approaches have been developed in recent years [5]. For example, new-generation proteasome inhibitors including carfilzomib, ixazomib, and marizomib are active even in the setting of bortezomib-resistant MM. Pomalidomide, a next-generation immunomodulatory drug, has shown activity even in 17p (p53) deleted MM [6]. Excitingly, monoclonal
\end{abstract}

\footnotetext{
Offprint requests to: Naoya Mimura, Department of Transfusion Medicine and Cell Therapy, Chiba University Hospital, 1-8-1 Chuoku, Chiba 260-8677, JAPAN; naoyamimura@ @ chiba-u.jp. Kenneth C. Anderson, Dana-Farber Cancer Institute, Mayer 557, 450 Brookline Ave., Boston, MA 02215, USA; kenneth_anderson@dfci.harvard.edu.

Publisher's Disclaimer: This is a PDF file of an unedited manuscript that has been accepted for publication. As a service to our customers we are providing this early version of the manuscript. The manuscript will undergo copyediting, typesetting, and review of the resulting proof before it is published in its final citable form. Please note that during the production process errors may be discovered which could affect the content, and all legal disclaimers that apply to the journal pertain.

Conflict of interest disclosure

K.C.A. serves on advisory boards to Celgene, Onyx, Sanofi-Aventis, and Gilead. The remaining authors declare no competing financial interests.
} 
antibodies such as elotuzumab (anti-SLAMF7, also known as CS1) and daratumumab (antiCD38) show promising clinical efficacy, especially in combination with lenalidomide. In this review, we focus on new therapeutic approaches to increase endoplasmic reticulum stress, target signal transduction, trigger epigenetic modulation, as well as induce anti-MM immune responses in the BM niche. The overview of novel therapeutic approaches is shown in Figure 1.

\section{Targeting the unfolded protein response induced by endoplasmic reticulum stress}

The endoplasmic reticulum (ER) is a cellular organelle responsible for gluconeogenesis, lipid synthesis, and $\mathrm{Ca}^{2+}$ storage. In the ER, secretory or membrane proteins are folded properly to form their functional structure. However, extracellular insults/stress such as low nutrients, hypoxia, or drugs can disrupt protein synthesis and folding, thereby inducing accumulation of misfolded proteins in the ER and resulting in increased ER stress. The unfolded protein response (UPR) is an adaptive response to ER stress condition by increasing biosynthetic capacity and decreasing the biosynthetic burden on the ER in order to maintain cellular homeostasis and cell survival [7, 8]. However, when the stress cannot be compensated by the UPR, apoptosis is then triggered as a terminal cellular response [9]. In general, activation of the UPR is initiated through three different ER transmembrane proteins and their downstream pathways: inositol-requiring enzyme 1a (IRE1a), protein kinase RNA (PKR)-like ER kinase (PERK), and activating transcription factor 6 (ATF6). During unstressed conditions, these proteins are inactivated by interacting with molecular chaperone immunoglobulin-heavy-chain-binding protein (BiP)/GRP78. However, when unfolded proteins accumulate in the ER, then BiP/GRP78 dissociates from these sensor proteins to prevent aberrant aggregation of the proteins, thereby triggering downstream UPR signaling [10].

During the UPR, IRE1a is oligomerized and autophosphorylated, followed by activation of its endoribonuclease domain and triggering of splicing of X-box binding protein 1 (XBP1) mRNA. More specifically, activated IRE1a endoribonuclease cleaves a 26 nucleotide intron from XBP1 mRNA, resulting in a translational frame-shift to turn unspliced XBP1 (XBP1u: inactive) into spliced XBP1 (XBP1s: active) [11]. XBP1 acts as a crucial transcription factor in the UPR, regulating genes responsible for protein folding and ER associated degradation (ERAD) to process misfolded proteins [12]. PERK is a serine/threonine kinase which phosphorylates eukaryotic translation-initiation factor $2 a$ (eIF2a), leading to inhibition of the translation of new protein synthesis and thereby reducing protein overload in the ER [13]. In the UPR, ATF6 is transported to the Golgi apparatus and cleaved into active transcription factor regulating ER chaperones, including XBP1 [14]. Importantly, under prolonged and uncompensated stress conditions, the UPR triggers cellular apoptosis, also called terminal UPR. In this process, a pro-apoptotic transcription factor C/EBP homologous protein (CHOP), also known as GADD153, is induced via PERK and downstream ATF4 pathways, with downregulation of BCL2 followed by caspase-dependent apoptosis $[15,16]$.

Exp Hematol. Author manuscript; available in PMC 2016 August 01. 
Myeloma cells produce excess M proteins that cause high basal levels of ER stress and require strict ER quality control for protein synthesis. Therefore, targeting the UPR induced by ER stress represents a promising novel therapeutic strategy in MM [17, 18].

\subsection{Ubiquitin-proteasome system}

Bortezomib, a dipeptide boronic acid analogue mediating selective and reversible inhibition of the $26 \mathrm{~S}$ proteasome, has dramatically changed the outcome of MM patients [19, 20]. Since a number of proteins are substrates of the proteasome, one of the major cytotoxic mechanisms induced by bortezomib is increased ER stress [21]. More specifically, the ubiquitin-proteasome pathway facilitates the removal of misfolded proteins accumulated in the ER by induction of the ERAD; conversely, bortezomib blocks this pathway and induces the terminal UPR, thereby leading to apoptosis via upregulation of CHOP. Following the remarkable success of bortezomib, different classes of proteasome inhibitors with reversible and/or irreversible inhibition of chymotrypsin-like, trypsin-like, and/or caspase-like activities, have been developed. All these agents inhibit activity of the 20S proteasome and have similar biologic impact in MM cells [22]. Indeed, we have confirmed that carfilzomib, a 20 S proteasome inhibitor with irreversibly chymotrypsin-like activity, also triggers the ER stress response in MM cells [23].

\subsection{Heat shock proteins}

Heat shock proteins (HSP) were initially defined as a family of proteins induced by heat shock, that act as molecular chaperones to stabilize and/or correctly fold their client proteins [24]. Among these HSPs, HSP90 is the most well-investigated in many cancers, including MM. HSP90 is a highly conserved molecular chaperone which interacts with numerous number of client proteins with crucial roles in cancer pathogenesis. Therefore, HSP90 is an attractive therapeutic target in cancer [25]. In MM, HSP90 is abundantly expressed and mediates the anti-apoptotic effects conferred by the BM microenvironment by maintaining client proteins involved in critical signaling pathways including NF- $\kappa \mathrm{B}$, phosphatidylinositol 3-kinase (PI3K)/Akt, and RAS/ mitogen-activated protein kinase (MAPK) which mediate MM cell survival, drug resistance, and proliferation, respectively [26]. A geldanamycin analog 17-allylamino-17-demethoxy-geldanamycin (17-AAG) has been extensively studied in preclinical models of MM: it increases UPR components including CHOP protein, triggering terminal UPR followed by cell death via apoptosis [27]. Inhibition of HSP90 triggers ER stress both by preventing HSP90 from folding proteins properly via GRP94 in the ER and by destabilizing the ER-stress sensor IRE1a [28, 29]. Although HSP90 inhibitors demonstrate promising anti-tumor effects in preclinical studies, some clinical trials have been discontinued due to adverse effects [25]. Among these side effects, ocular toxicity is the dose-limiting factor, which should be avoided by nextgeneration HSP90 inhibitors. Indeed, Suzuki et al. have recently reported that a novel HSP90a/ $\beta$ selective inhibitor TAS-116 exhibits anti-MM activities in preclinical settings without ocular toxicity [30].

HSP70 inhibitors also show significant anti-MM activities [31, 32]. Since HSP70 is increased as a compensatory response to HSP90 inhibition, dual inhibition of HSP90 and 70 may be a promising therapeutic option [33]. Moreover, targeting upstream of HSP is also 
promising in MM therapy: inhibition of heat shock transcription factor 1 (HSF1), which regulates multiple HSPs including HSP90, 70, and 27, induces apoptosis in MM cells [34]. Interestingly, the inhibition of PI3K/Akt pathway downregulates HSF1 and downstream HSP70, sensitizing MM cells to HSP90 inhibition [35].

\subsection{IRE1a-XBP pathway}

Among the three cascades of the UPR, IRE1a-XBP pathway has been most extensively studied in cancers, including MM [36]. XBP1 is required for differentiation to normal plasma cells [37] and is overexpressed in human MM cells [38]. Moreover, knockdown of XBP1 sensitizes MM cells to cell stress-induced apoptosis [39], whereas overexpression of its spliced variant (XBP1s) has been used to generate a murine model of MM, further supporting its critical role in MM pathogenesis [40]. Based on these reports, the therapeutic potential of targeting XBP1 has been investigated in MM. For example, targeting XBP1 splicing by inhibiting IRE1a has triggered anti-tumor activities in preclinical studies [41-45]. We have demonstrated that an IRE1a RNase domain selective inhibitor MKC-3946 blocks XBP1 splicing, which is associated with modest MM cell growth inhibition in vitro. Importantly, however, it significantly inhibits tumor growth in a mouse xenograft model of human MM [42], suggesting that basal levels of ER stress may be higher in vivo in the tumor microenvironment due to hypoxia or low levels of nutrients. Moreover, MKC-3946 significantly enhances ER stress and cytotoxicity induced by bortezomib or 17-AAG in vitro; it also enhances tumor growth inhibition in combination with bortezomib in vivo in a xenograft murine model, suggesting potential clinical utility of combination treatment.

A recent study has demonstrated that BM cellular components such as BM stromal cells (BMSCs) and osteoclasts are dependent of XBP1 splicing. Since the BM microenvironment plays a crucial role in MM cell pathogenesis, modulation of XBP1s represents a novel therapeutic approach in MM in the context of the BM milieu [46]. Moreover, XBP1 may also be a therapeutic target in immunotherapy, since vaccination of smoldering MM patients with human leukocyte antigen (HLA)-A2(+) immunogenic peptides derived from XBP1 antigens can induce a tumor-specific cytotoxic T-cell response [47-49].

Contribution of basal level of XBP1 to the treatment response is still controversial. For example, lower XBP1s/u ratio is correlated with better response to thalidomide treatment [50]; in contrast, bortezomib is more effective in patients with high XBP1 levels [51, 52]. More recently, Leung-Hagesteijn et al. have reported that XBP1s is required for bortezomibinduced cytotoxicity in MM; and conversely, that the XBP1s-negative MM subset with arrested secretory maturation becomes resistant to bortezomib [53]. Although MM cells with high XBP1s are more sensitive to proteasome inhibitors due to high basal levels of ER stress, inhibition of XBP1 splicing can enhance response to bortezomib in this setting.

Regarding other ER stress sensor proteins, ATF6 and PERK, a previous study has reported that downregulation of either ATF6 or PERK triggers MM cell death, due to induction of autophagy especially by PERK silencing [54]. These results further confirm the UPR as a potential therapeutic target in MM. 


\section{Targeting signal transduction}

The Interaction of MM cells with BMSCs stimulates secretion of IL-6, IGF-1, VEGF, SDF1a, TGF $\beta$, HGF, and TNFa from both BMSCs and MM cells. These cytokines activate multiple signaling pathways in MM cells, including the phosphatidylinositol 3-kinase (PI3K)/Akt pathway, JAK/STAT3 pathway, RAS/RAF/MEK/ERK pathway, and NF- $\kappa B$ pathway, resulting in cell growth, anti-apoptosis, and drug resistance in MM cells [55, 56]. Therefore, the molecules in these signaling cascades represent therapeutic targets in MM.

\subsection{PI3K/Akt pathway}

PI3K/Akt pathway has been extensively studied in various types of cancers, including MM, and mediates tumor cell survival, growth, and drug resistance [57-60]. Among the three classes of PI3K, class I PI3K is composed of a catalytic subunit p110 and an adaptor/ regulatory subunit $\mathrm{p} 85$, and may be the most relevant in MM pathogenesis. It is activated via upstream receptor tyrosine kinases by various growth factors and/or cytokines at the inner membrane, followed by phosphorylation and activation of downstream serine-threonine protein kinase Akt (also known as protein kinase B). Akt in turn phosphorylates and activates many substrates, including GSK3a/ $\beta$ and FKHR proteins, to facilitate cell proliferation, survival, and protection against apoptosis [57, 61, 62]. Akt also mediates activation of mammalian target of rapamycin (mTOR), a key regulator of cell metabolism and autophagy $[63,64]$. Since the PI3K/Akt pathway is activated by many cytokines and cell adhesion to BMSCs, it plays a crucial role in MM cell survival and drug resistance in the context of the BM microenvironment [55, 56, 65, 66]. Therefore, targeting PI3K/Akt pathway is a promising therapeutic option in MM [59, 67].

Akt, a master regulator in this pathway, has been extensively investigated in both preclinical and clinical studies in MM. We have previously shown that an alkylphospholipid perifosine, which inhibits Akt activity [68, 69], shows anti-MM activities and enhances MM cytotoxicity induced by bortezomib in preclinical setting [70]; however, it has off-target effects [70, 71]. Clinical trials of perifosine in MM were discontinued due to limited clinical response. A recent study has shown the in-vitro efficacy of a selective Akt inhibitor MK-2206 [72]. Most recently, we have demonstrated that a selective and potent allosteric Akt inhibitor TAS-117 induces significant growth inhibition in MM cells in vitro and in vivo [23]. TAS-117 triggers both apoptosis and autophagy, as well as ER stress response. Importantly, TAS-117 enhances cytotoxicity induced by proteasome inhibitors (bortezomib and carfilzomib) by inhibition of proteasome inhibitor-induced Akt activation and induction of fatal ER stress, associated with increased CHOP expression. These results suggest cross talk between Akt pathway and unfolded protein response in MM cells. Indeed, previous studies have shown that Akt inhibition activates PERK pathway in the UPR [73]. Moreover, an ATP-competitive Akt inhibitor afuresertib exhibits safety and clinical activity in a phase I clinical trial [74], suggesting the clinical potential of selective Akt inhibitors in MM. In addition to direct effects on MM cells, Akt inhibition also affects BM cellular components. For example, we found that TAS-117 inhibits IL-6 secretion from BMSCs by modulating NF- $\kappa$ B activity [23]. Moreover, Akt inhibition blocks osteoclastogenesis and bone 
osteolysis, further supporting clinical utility of Akt inhibitors in MM patients with bone disease [75].

Small molecule PI3K inhibitors have also been developed [61]. Ikeda et al. have reported that the blockade of $\mathrm{p} 110 \delta$, a component of class I PI3K, triggers apoptosis and autophagy in vitro, as well as inhibits tumor growth in preclinical in-vivo models [76]. mTOR inhibitors, such as rapamycin and its analogues everolimus and temsirolimus, have also been investigated in the treatment of cancers, including MM. While these drugs inhibit only mTORC1 and lead to activation of Akt due to negative feedback of mTORC2 [77], dual inhibition of mTORC1 and mTORC2 in MM cells demonstrates significant growth inhibition [78]. Moreover, dual inhibition of PI3K/mTOR or insulin-like growth factor 1 receptor (IGF1R)/mTOR also triggers significant anti-tumor effects in MM [79, 80].

\subsection{Other signaling pathways}

RAS/RAF/MEK/ERK pathway plays a pivotal role in the pathogenesis of MM, and high frequency of mutations in NRAS, KRAS and BRAF genes have been reported [81]. Although small molecule inhibitors targeting this pathway (e.g. MEK inhibitor selumetinib) have been developed and show remarkable anti-tumor effects in preclinical settings, their clinical activities to date are limited [82]. Importantly, this pathway is upregulated by Akt inhibition, and dual inhibition of both pathways using Akt inhibitors and MEK inhibitors shows synergistic anti-tumor effects [70, 72, 83]. More recently, 3-phosphoinositidedependent protein kinase 1 (PDPK1) inhibitor has been shown to induce growth inhibition and apoptosis in MM cells through blockade of both RSK2, a mediator of MAPK/ERK pathway, and Akt [84], further indicating potential clinical utility.

NF- $\kappa \mathrm{B}$ signaling pathway also plays a key role in the pathogenesis of MM, by transcriptional regulation of genes involved in proliferation, survival, and drug resistance [85]. NF- $\kappa \mathrm{B}$ activity in MM cells is mediated via both canonical and non-canonical pathways. Bortezomib was considered to acts as a canonical NF- $\kappa \mathrm{B}$ inhibitor by blocking proteasomal degradation of I $\mathrm{B} \mathrm{B}$; however, bortezomib activates constitutive canonical NF$\kappa \mathrm{B}$ activity in MM cells, and the combination of bortezomib with IKK $\beta$ inhibitor triggers synergistic MM cell growth inhibition [86]. Importantly, there is cross-talk signaling between canonical and non-canonical pathways: inhibition of non-canonical pathway activates canonical pathway and vice versa. Indeed, Fabre at al. reported that PBS-1086, a small molecule inhibitor which simultaneously blocks both canonical and non-canonical NF- $\kappa B$ pathways, induces significant MM cell growth inhibition, even in bortezomibresistant cells [87].

\section{Targeting epigenetic modulation}

In the development of myeloma, stepwise gene mutations in cells are accumulated, resulting in genetic complexity and molecular heterogeneity. Importantly, chromosomal deletions or gains, translocations, as well as point mutations, are correlated with clinical features and prognosis in MM [81, 88]. Moreover "epigenetic modification", defined as alteration of gene expression without alteration of DNA sequences, is also important in the pathogenesis of cancers, including MM $[89,90]$. Specifically, epigenetic modifications are categorized 
into two major types: DNA methylation and histone modification. Indeed, many oncogenes and tumor-suppressor genes are affected by these epigenetic modifications. Therefore, epigenetic therapies are under evaluation in many cancers. In MM, aberrant DNA methylation with affected expression of specific genes is observed during disease development and progression [91, 92]. However, the mechanisms of aberrant DNA methylation in MM remain unclear; therefore, targeting DNA methylation has not yet been fully developed. In contrast, histone modifications have been characterized, and histone deacetylase inhibitors have already shown promising results in MM. Histones are major protein components of chromatin, where they complex with DNA to form the nucleosome. The lysine residues of histone tails can undergo various chemical modifications including acetylation, methylation, ubiquitination, phosphorylation, and sumoylation, which alter gene transcription [93].

\subsection{Histone acetylation}

Gene transcription is actively regulated by histone acetylation, which is strictly mediated by both histone acetyltransferases (HATs) and histone deacetylases (HDACs). Therefore, HDACs are an attractive therapeutic target in cancers including MM. HDACs consist of 4 classes according to their structure, localization, and function: class I (HDAC 1,2,3, and 8), class IIa (HDAC 4,5,7, and 9), class IIb (HDAC 6 and 10), class III (also known as sirtuins), and class IV (HDAC11) [94, 95]. Importantly, HDACs target not only histones, but also non-histone proteins in cancer cells [96]. These proteins relevant in MM pathogenesis include HSP90, p53, STAT3, $\beta$-catenin, Sp1, c-Myc, Rel-A, phosphatase and tensin homolog (PTEN), murine double minute 2 (MDM2), and tubulin [97]. In preclinical studies, non-selective HDAC inhibitors show anti-tumor activities. Class I and II HDAC inhibitors such as vorinostat (also known as SAHA) [98], MVP-LAQ824 (LAQ824) [99], panobinostat (LBH589) [100, 101], and belinostat (PXD101) [102] show anti-tumor effects in MM. A class I HDAC inhibitor romidepsin (FR901228, FK228) [103] also induces apoptosis in MM cells. Although non-selective HDAC inhibitors such as vorinostat combined with bortezomib have shown efficacy, the progression-free survival (PFS) advantage of combination versus bortezomib with placebo was less than one month due to attendant toxicities including fatigue, diarrhea, and thrombocytopenia [104]. Of note, panobinostat (LBH589) has been FDA approved for treatment of relapsed MM due to 4-month PFS advantage of panobinostat with bortezomib/dexamethasone versus bortezomib/ dexamethasone alone [105]. .

To avoid the side effects due to broad inhibition by non-selective HDAC inhibitors, classand/or isoform-selective HDAC inhibitors have recently been developed. Specifically, HDAC6 plays a crucial role in aggresome formation, an alternative system for degradation of ubiquitinated proteins in the lysosome, binding to misfolded ubiquitinated proteins on the one hand and to dynein motility complexes on the other to shuttle proteins to the aggresome. Therefore, HDAC6 inhibitors coupled with bortezomib can block ubiquitinated protein degradation in both proteasomes and lysosomes. Indeed, first-in-class HDAC6-selective inhibitor tubacin shows synergistic MM cytotoxicity with bortezomib, associated with significant accumulation of polyubiquitinated proteins and cell stress [106]. Based on this encouraging result, a selective HDAC6 inhibitor ricolinostat (ACY-1215) has subsequently 
been developed for clinical use. It shows synergistic anti-MM activities with both bortezomib and lenalidomide in preclinical setting [107, 108], and derived phase I/II clinical trials in MM are ongoing $[109,110]$. The combination of HDAC6 inhibitors with the second-generation proteasome inhibitor carfilzomib shows even more potent in-vitro synergistic cytotoxicity than bortezomib, providing the rationale for clinical trials of this combination [111]. Finally, Minami et al. have shown that an HDAC3-selective inhibitor BG45, alone and in combination with bortezomib, triggers significant anti-MM activities both in vitro and in vivo [112].

\subsection{Histone methylation}

MM set domain (MMSET, also known as WHSC1/NSD2) is a histone methyltransferase overexpressed by $\mathrm{t}(4 ; 14)$ subset $(15 \%)$ of $\mathrm{MM}$ and associated with poor prognosis. MMSET mainly induces dimethylation of lysine 36 at histone $\mathrm{H} 3$ (H3K36me2), leading to active target gene transcription [113]. MMSET plays a crucial role in pathogenesis of $t(4 ; 14) \mathrm{MM}$ by promoting cell proliferation through repression of miR-126* and subsequent enhancement of c-MYC protein levels $[114,115]$. Therefore, MMSET is a therapeutic target in $\mathrm{t}(4 ; 14) \mathrm{MM}$, and selective inhibitors are under development.

Enhancer of zeste homolog 2 (EZH2) is a histone-lysine N-methyltransferase, which also represents a novel therapeutic target in MM. EZH2 is the catalytic component of polycomb repressive complex 2 (PRC2), which triggers $\mathrm{H} 3 \mathrm{~K} 27 \mathrm{me} 3$ to repress the transcription of target genes, thereby promoting growth in cancers, including lymphoma [116]. Moreover, EZH2 is overexpressed with progression from MGUS to MM [117]. Importantly, EZH2 knockdown leads to inhibition of MM cell growth [118]. In contrast, ubiquitously transcribed tetratricopeptide repeat X chromosome (UTX, also known as KDM6A), a histone demethylase which removes methyl groups at H3K27, is inactive due to mutation in a subset of MM cases [119], suggesting that increased H3K27me3 by UTX inactivation contributes to MM pathogenesis. Indeed, Rizq et al. have reported that an EZH2 inhibitor UNC1999 demonstrates both in-vitro and in-vivo anti-tumor activities in MM [120].

\subsection{Other epigenetic targets}

MicroRNAs (miRNAs) are a class of noncoding RNAs which regulate gene expression and are associated with oncogenic or tumor-suppressive functions [121]. Indeed, abnormal expression of various miRNAs contributes to pathogenesis of MM [122]. Among these miRNAs, miR-29b reduces global DNA methylation and inhibits cell cycle progression in $\mathrm{MM}$, and synthetic miR-29b mimics exert in-vivo anti-MM activity in preclinical models [123]. miR-34a also acts as a negative regulator of MM cell growth, and systemic delivery of formulated miR-34a inhibits growth of MM xenografts in SCID mice [124]. Ongoing investigations are evaluating therapeutic systems to assure optimal delivery of miRNAs to MM cells [125].

Another possible epigenetic target in MM are bromodomains, which act as a reader of epigenetic marks to recognize acetylated lysine residues at histone tails, thereby leading to modulation of chromatin structure and target gene expression [126]. A selective small molecule inhibitor of bromodomain protein BRD4, JQ1 [127], has demonstrated potent anti- 
MM activities both in vitro and in vivo, associated with downregulation of c-Myc [128], and clinical trials of BRD4 inhibitors in MM are ongoing.

\section{Targeting immune system in the bone marrow microenvironment}

Immune surveillance system is impaired in MM patients, providing the impetus to develop strategies to restore host anti-MM immunity [129]. Allogeneic stem cell transplantation (AlloSCT) can provide a potent donor graft-versus-MM effect and lead to long-term disease free survival. However, due to treatment-related morbidity and mortality, alloSCT is utilized only in the context of a clinical trial to avoid attendant toxicity while exploiting graft-versusMM effect [130]. To date, the most successful immune-based approach in MM is immunomodulatory drugs (IMiDs) thalidomide, lenalidomide, and pomalidomide. A recent study has shown that the direct anti-MM activity of IMiDs is mediated via binding to E3 ubiquitin ligase cereblon, triggering proteasomal degradation of Ikaros family zinc finger proteins 1 and 3 (IKZF1 and IKZF3) [131]. The immunomodulatory effects by IMiDs include activation of natural killer (NK) or NKT cells, stimulation of both CD4+ and CD8+ $\mathrm{T}$ cells, and inhibition of regulatory $\mathrm{T}$ cells $[132,133]$. Interestingly, IMiDs induce epigenetic modification of suppressor of cytokine signaling (SOCS) 1 gene in MM cells and modulate SOCS1-mediated cytokine signaling in immune effector cells, thereby integrating immune responses against MM cells [134].

\subsection{Immunological checkpoint PD-1/PD-L1}

Programmed cell death 1 (PD-1) is a type I transmembrane protein expressed on the surface of activated T cells, interacting with its two ligands PD-L1 and PD-L2. The association between PD-L1 on target cells and PD-1 on T and effector cells acts as an immunological checkpoint to suppress anti-tumor immunity [135]. Indeed, PD-1 is largely expressed on tumor-infiltrating T cells, and PD-L1 is upregulated on multiple human solid tumors, allowing tumor cells to escape from host immune response [136]. Recently, a series of studies have demonstrated the remarkable clinical efficacy of PD-1/PD-L1 blockade in cancers including melanoma, lung cancer, and lymphoma [137-140]. Importantly, MM cells express PD-L1, which is further upregulated in the BM microenvironment [141, 142]. Furthermore, PD-1 expression is upregulated on NK or T cells in MM patients [143, 144]. These results indicate that the PD-1/PD-L1 axis plays crucial roles in host immune surveillance in MM. Indeed, growth of MM cells is inhibited in PD-1-deficient mice [145], and an anti-PD-1 antibody CT-011 both enhances NK-cell cytotoxicity against MM cells [143] and also enhances activated T-cell responses to vaccination with autologous dendritic/MM cell fusion [144]. PD-L1 blockade also contributes to inhibition of MM-tumor growth [145], and anti-PD-L1 therapy in combination with lymphodepletive irradiation facilitates T cell-mediated anti-MM activity [146]. Although autologous stem cell transplantation in combination with cell-base vaccine administration does not prolong survival in the 5T33 murine model of MM, addition of PD-L1 blockade to this combination treatment prolongs host survival [147]. These reports suggest that targeting PD-1/PD-L1 pathway holds great promise in the treatment of MM patients [148], alone or in combination with other immune-based therapies including monoclonal antibodies, immunomodulatory drugs, and/or vaccines. 


\subsection{Myeloid-derived suppressor cells}

Myeloid-derived suppressor cells (MDSCs) are a population of early myeloid cells which are expanded in the tumor microenvironment and suppress T-cell proliferation and cytokine production, while promoting tumor cell growth $[149,150]$. In MM, the number of MDSCs is increased in both peripheral blood and BM [151, 152]. Moreover, MDSCs facilitate the growth of MM cells through suppression of T cell-mediated immune responses [151]. Interestingly, phosphodiestrerase-5 (PDE5) inhibitors have been reported to reduce the function of MDSCs [153], and treatment with a PDE5 inhibitor resulted in a dramatic clinical response in a patient with end-stage relapsed/refractory MM, associated with decreased MDSCs [154].

\section{Future directions and closing remarks}

In this article, we have discussed the potential of novel targeted therapeutic approaches in MM, which still remains incurable with current therapeutic options. Since MM is heterogeneous, associated with complex gene abnormalities and multiple signaling aberrations, the strategy of targeting single genes, gene products, or single signaling pathways may not suppress MM cell growth. Therefore, combination strategies are still key for MM treatment, targeting not only MM cells, but also the tumor microenvironment, including host immunity. In order to reach the goal to conquer this intractable cancer, further new treatment options with novel therapeutics should be developed.

\section{Acknowledgments}

Our work was supported by National Institutes of Health Specialized Programs of Research Excellence (SPORE) grant P50100707, PO1-CA078378 and RO1 CA050947. KCA is an American Cancer Society Clinical Research Professor.

\section{References}

[1]. Laubach J, Richardson P, Anderson K. Multiple myeloma. Annu Rev Med. 2011; 62:249-264. [PubMed: 21090965]

[2]. Palumbo A, Anderson K. Multiple myeloma. N Engl J Med. 2011; 364:1046-1060. [PubMed: 21410373]

[3]. Kumar SK, Rajkumar SV, Dispenzieri A, et al. Improved survival in multiple myeloma and the impact of novel therapies. Blood. 2008; 111:2516-2520. [PubMed: 17975015]

[4]. Mahindra A, Laubach J, Raje N, Munshi N, Richardson PG, Anderson K. Latest advances and current challenges in the treatment of multiple myeloma. Nat Rev Clin Oncol. 2012; 9:135-143. [PubMed: 22349016]

[5]. Ocio EM, Richardson PG, Rajkumar SV, et al. New drugs and novel mechanisms of action in multiple myeloma in 2013: a report from the International Myeloma Working Group (IMWG). Leukemia. 2014; 28:525-542. [PubMed: 24253022]

[6]. Leleu X, Karlin L, Macro M, et al. Pomalidomide plus low-dose dexamethasone in multiple myeloma with deletion 17p and/or translocation (4;14): IFM 2010-02 trial results. Blood. 2015; 125:1411-1417. [PubMed: 25575538]

[7]. Schroder M, Kaufman RJ. The mammalian unfolded protein response. Annu Rev Biochem. 2005; 74:739-789. [PubMed: 15952902]

[8]. Walter P, Ron D. The unfolded protein response: from stress pathway to homeostatic regulation. Science. 2011; 334:1081-1086. [PubMed: 22116877] 
[9]. Kim I, Xu W, Reed JC. Cell death and endoplasmic reticulum stress: disease relevance and therapeutic opportunities. Nat Rev Drug Discov. 2008; 7:1013-1030. [PubMed: 19043451]

[10]. Todd DJ, Lee AH, Glimcher LH. The endoplasmic reticulum stress response in immunity and autoimmunity. Nat Rev Immunol. 2008; 8:663-674. [PubMed: 18670423]

[11]. Yoshida H, Matsui T, Yamamoto A, Okada T, Mori K. XBP1 mRNA is induced by ATF6 and spliced by IRE1 in response to ER stress to produce a highly active transcription factor. Cell. 2001; 107:881-891. [PubMed: 11779464]

[12]. Lee AH, Iwakoshi NN, Glimcher LH. XBP-1 regulates a subset of endoplasmic reticulum resident chaperone genes in the unfolded protein response. Mol Cell Biol. 2003; 23:7448-7459. [PubMed: 14559994]

[13]. Harding HP, Zhang Y, Ron D. Protein translation and folding are coupled by an endoplasmicreticulum-resident kinase. Nature. 1999; 397:271-274. [PubMed: 9930704]

[14]. Yoshida H, Okada T, Haze K, et al. ATF6 activated by proteolysis binds in the presence of NF-Y $(\mathrm{CBF})$ directly to the cis-acting element responsible for the mammalian unfolded protein response. Mol Cell Biol. 2000; 20:6755-6767. [PubMed: 10958673]

[15]. McCullough KD, Martindale JL, Klotz LO, Aw TY, Holbrook NJ. Gadd153 sensitizes cells to endoplasmic reticulum stress by down-regulating $\mathrm{Bcl} 2$ and perturbing the cellular redox state. Mol Cell Biol. 2001; 21:1249-1259. [PubMed: 11158311]

[16]. Tabas I, Ron D. Integrating the mechanisms of apoptosis induced by endoplasmic reticulum stress. Nat Cell Biol. 2011; 13:184-190. [PubMed: 21364565]

[17]. Aronson LI, Davies FE. DangER: protein ovERload. Targeting protein degradation to treat myeloma. Haematologica. 2012; 97:1119-1130. [PubMed: 22580998]

[18]. Vincenz L, Jager R, O'Dwyer M, Samali A. Endoplasmic reticulum stress and the unfolded protein response: targeting the Achilles heel of multiple myeloma. Mol Cancer Ther. 2013; 12:831-843. [PubMed: 23729400]

[19]. Richardson PG, Sonneveld P, Schuster MW, et al. Bortezomib or high-dose dexamethasone for relapsed multiple myeloma. N Engl J Med. 2005; 352:2487-2498. [PubMed: 15958804]

[20]. San Miguel JF, Schlag R, Khuageva NK, et al. Bortezomib plus melphalan and prednisone for initial treatment of multiple myeloma. N Engl J Med. 2008; 359:906-917. [PubMed: 18753647]

[21]. Obeng EA, Carlson LM, Gutman DM, Harrington WJ Jr. Lee KP, Boise LH. Proteasome inhibitors induce a terminal unfolded protein response in multiple myeloma cells. Blood. 2006; 107:4907-4916. [PubMed: 16507771]

[22]. Hideshima T, Anderson KC. Biologic impact of proteasome inhibition in multiple myeloma cells--from the aspects of preclinical studies. Semin Hematol. 2012; 49:223-227. [PubMed: 22726545]

[23]. Mimura N, Hideshima T, Shimomura T, et al. Selective and potent Akt inhibition triggers antimyeloma activities and enhances fatal endoplasmic reticulum stress induced by proteasome inhibition. Cancer Res. 2014; 74:4458-4469. [PubMed: 24934808]

[24]. Macario AJ, Conway de Macario E. Sick chaperones, cellular stress, and disease. N Engl J Med. 2005; 353:1489-1501. [PubMed: 16207851]

[25]. Garcia-Carbonero R, Carnero A, Paz-Ares L. Inhibition of HSP90 molecular chaperones: moving into the clinic. Lancet Oncol. 2013; 14:e358-369. [PubMed: 23896275]

[26]. Mitsiades CS, Mitsiades NS, McMullan CJ, et al. Antimyeloma activity of heat shock protein-90 inhibition. Blood. 2006; 107:1092-1100. [PubMed: 16234364]

[27]. Davenport EL, Moore HE, Dunlop AS, et al. Heat shock protein inhibition is associated with activation of the unfolded protein response pathway in myeloma plasma cells. Blood. 2007; 110:2641-2649. [PubMed: 17525289]

[28]. Lawson B, Brewer JW, Hendershot LM. Geldanamycin, an hsp90/GRP94-binding drug, induces increased transcription of endoplasmic reticulum (ER) chaperones via the ER stress pathway. $\mathrm{J}$ Cell Physiol. 1998; 174:170-178. [PubMed: 9428803]

[29]. Marcu MG, Doyle M, Bertolotti A, Ron D, Hendershot L, Neckers L. Heat shock protein 90 modulates the unfolded protein response by stabilizing IRE1alpha. Mol Cell Biol. 2002; 22:8506-8513. [PubMed: 12446770] 
[30]. Suzuki R, Hideshima T, Mimura N, et al. Anti-tumor activities of selective HSP90alpha/beta inhibitor, TAS-116, in combination with bortezomib in multiple myeloma. Leukemia. 2014

[31]. Braunstein MJ, Scott SS, Scott CM, et al. Antimyeloma Effects of the Heat Shock Protein 70 Molecular Chaperone Inhibitor MAL3-101. J Oncol. 2011; 2011:232037. [PubMed: 21977030]

[32]. Zhang L, Fok JJ, Mirabella F, et al. Hsp70 inhibition induces myeloma cell death via the intracellular accumulation of immunoglobulin and the generation of proteotoxic stress. Cancer Lett. 2013; 339:49-59. [PubMed: 23887058]

[33]. Davenport EL, Zeisig A, Aronson LI, et al. Targeting heat shock protein 72 enhances Hsp90 inhibitor-induced apoptosis in myeloma. Leukemia. 2010; 24:1804-1807. [PubMed: 20703255]

[34]. Heimberger T, Andrulis M, Riedel S, et al. The heat shock transcription factor 1 as a potential new therapeutic target in multiple myeloma. Br J Haematol. 2013; 160:465-476. [PubMed: 23252346]

[35]. Chatterjee M, Andrulis M, Stuhmer T, et al. The PI3K/Akt signaling pathway regulates the expression of Hsp70, which critically contributes to Hsp90-chaperone function and tumor cell survival in multiple myeloma. Haematologica. 2013; 98:1132-1141. [PubMed: 23065523]

[36]. Koong AC, Chauhan V, Romero-Ramirez L. Targeting XBP-1 as a novel anti-cancer strategy. Cancer Biol Ther. 2006; 5:756-759. [PubMed: 16861911]

[37]. Iwakoshi NN, Lee AH, Glimcher LH. The X-box binding protein-1 transcription factor is required for plasma cell differentiation and the unfolded protein response. Immunol Rev. 2003; 194:29-38. [PubMed: 12846805]

[38]. Munshi NC, Hideshima T, Carrasco D, et al. Identification of genes modulated in multiple myeloma using genetically identical twin samples. Blood. 2004; 103:1799-1806. [PubMed: 12969976]

[39]. Lee AH, Iwakoshi NN, Anderson KC, Glimcher LH. Proteasome inhibitors disrupt the unfolded protein response in myeloma cells. Proc Natl Acad Sci U S A. 2003; 100:9946-9951. [PubMed: 12902539]

[40]. Carrasco DR, Sukhdeo K, Protopopova M, et al. The differentiation and stress response factor XBP-1 drives multiple myeloma pathogenesis. Cancer Cell. 2007; 11:349-360. [PubMed: 17418411]

[41]. Ali MM, Bagratuni T, Davenport EL, et al. Structure of the Ire1 autophosphorylation complex and implications for the unfolded protein response. EMBO J. 2011; 30:894-905. [PubMed: 21317875]

[42]. Mimura N, Fulciniti M, Gorgun G, et al. Blockade of XBP1 splicing by inhibition of IRE1alpha is a promising therapeutic option in multiple myeloma. Blood. 2012; 119:5772-5781. [PubMed: 22538852]

[43]. Ri M, Tashiro E, Oikawa D, et al. Identification of Toyocamycin, an agent cytotoxic for multiple myeloma cells, as a potent inhibitor of ER stress-induced XBP1 mRNA splicing. Blood Cancer J. 2012; 2:e79. [PubMed: 22852048]

[44]. Cross BC, Bond PJ, Sadowski PG, et al. The molecular basis for selective inhibition of unconventional mRNA splicing by an IRE1-binding small molecule. Proc Natl Acad Sci U S A. 2012; 109:E869-878. [PubMed: 22315414]

[45]. Papandreou I, Denko NC, Olson M, et al. Identification of an Ire1alpha endonuclease specific inhibitor with cytotoxic activity against human multiple myeloma. Blood. 2011; 117:1311-1314. [PubMed: 21081713]

[46]. Xu G, Liu K, Anderson J, et al. Expression of XBP1s in bone marrow stromal cells is critical for myeloma cell growth and osteoclast formation. Blood. 2012; 119:4205-4214. [PubMed: 22427205]

[47]. Bae J, Carrasco R, Lee AH, et al. Identification of novel myeloma-specific XBP1 peptides able to generate cytotoxic $\mathrm{T}$ lymphocytes: a potential therapeutic application in multiple myeloma. Leukemia. 2011; 25:1610-1619. [PubMed: 21660045]

[48]. Bae J, Prabhala R, Voskertchian A, et al. A multiepitope of XBP1, CD138 and CS1 peptides induces myeloma-specific cytotoxic T lymphocytes in T cells of smoldering myeloma patients. Leukemia. 2015; 29:218-229. [PubMed: 24935722] 
[49]. Bae J, Smith R, Daley J, et al. Myeloma-specific multiple peptides able to generate cytotoxic T lymphocytes: a potential therapeutic application in multiple myeloma and other plasma cell disorders. Clin Cancer Res. 2012; 18:4850-4860. [PubMed: 22753586]

[50]. Bagratuni T, Wu P, Gonzalez de Castro D, et al. XBP1s levels are implicated in the biology and outcome of myeloma mediating different clinical outcomes to thalidomide-based treatments. Blood. 2010; 116:250-253. [PubMed: 20421453]

[51]. Ling SC, Lau EK, Al-Shabeeb A, et al. Response of myeloma to the proteasome inhibitor bortezomib is correlated with the unfolded protein response regulator XBP-1. Haematologica. 2012; 97:64-72. [PubMed: 21993678]

[52]. Gambella M, Rocci A, Passera R, et al. High XBP1 expression is a marker of better outcome in multiple myeloma patients treated with bortezomib. Haematologica. 2014; 99:e14-16. [PubMed: 24497562]

[53]. Leung-Hagesteijn C, Erdmann N, Cheung G, et al. Xbp1s-negative tumor B cells and preplasmablasts mediate therapeutic proteasome inhibitor resistance in multiple myeloma. Cancer Cell. 2013; 24:289-304. [PubMed: 24029229]

[54]. Michallet AS, Mondiere P, Taillardet M, Leverrier Y, Genestier L, Defrance T. Compromising the unfolded protein response induces autophagy-mediated cell death in multiple myeloma cells. PloS one. 2011; 6:e25820. [PubMed: 22028791]

[55]. Hideshima T, Anderson KC. Molecular mechanisms of novel therapeutic approaches for multiple myeloma. Nat Rev Cancer. 2002; 2:927-937. [PubMed: 12459731]

[56]. Hideshima T, Mitsiades C, Tonon G, Richardson PG, Anderson KC. Understanding multiple myeloma pathogenesis in the bone marrow to identify new therapeutic targets. Nat Rev Cancer. 2007; 7:585-598. [PubMed: 17646864]

[57]. Vivanco I, Sawyers CL. The phosphatidylinositol 3-Kinase AKT pathway in human cancer. Nat Rev Cancer. 2002; 2:489-501. [PubMed: 12094235]

[58]. Bader AG, Kang S, Zhao L, Vogt PK. Oncogenic PI3K deregulates transcription and translation. Nat Rev Cancer. 2005; 5:921-929. [PubMed: 16341083]

[59]. Younes H, Leleu X, Hatjiharissi E, et al. Targeting the phosphatidylinositol 3-kinase pathway in multiple myeloma. Clin Cacer Res. 2007; 13:3771-3775.

[60]. Engelman JA. Targeting PI3K signalling in cancer: opportunities, challenges and limitations. Nat Rev Cancer. 2009; 9:550-562. [PubMed: 19629070]

[61]. Liu P, Cheng H, Roberts TM, Zhao JJ. Targeting the phosphoinositide 3-kinase pathway in cancer. Nat Rev Drug Discov. 2009; 8:627-644. [PubMed: 19644473]

[62]. Engelman JA, Luo J, Cantley LC. The evolution of phosphatidylinositol 3-kinases as regulators of growth and metabolism. Nat Rev Genet. 2006; 7:606-619. [PubMed: 16847462]

[63]. Pene F, Claessens YE, Muller O, et al. Role of the phosphatidylinositol 3-kinase/Akt and mTOR/ P70S6-kinase pathways in the proliferation and apoptosis in multiple myeloma. Oncogene. 2002; 21:6587-6597. [PubMed: 12242656]

[64]. Janku F, McConkey DJ, Hong DS, Kurzrock R. Autophagy as a target for anticancer therapy. Nat Rev Clin Oncol. 2011; 8:528-539. [PubMed: 21587219]

[65]. Hideshima T, Nakamura N, Chauhan D, Anderson KC. Biologic sequelae of interleukin-6 induced PI3-K/Akt signaling in multiple myeloma. Oncogene. 2001; 20:5991-6000. [PubMed: 11593406]

[66]. Mitsiades CS, Mitsiades N, Poulaki V, et al. Activation of NF-kappaB and upregulation of intracellular anti-apoptotic proteins via the IGF-1/Akt signaling in human multiple myeloma cells: therapeutic implications. Oncogene. 2002; 21:5673-5683. [PubMed: 12173037]

[67]. Keane NA, Glavey SV, Krawczyk J, O'Dwyer M. AKT as a therapeutic target in multiple myeloma. Expert Opin Ther Targets. 2014; 18:897-915. [PubMed: 24905897]

[68]. Kondapaka SB, Singh SS, Dasmahapatra GP, Sausville EA, Roy KK. Perifosine, a novel alkylphospholipid, inhibits protein kinase B activation. Mol Cancer Ther. 2003; 2:1093-1103. [PubMed: 14617782]

[69]. Ruiter GA, Zerp SF, Bartelink H, van Blitterswijk WJ, Verheij M. Anti-cancer alkyllysophospholipids inhibit the phosphatidylinositol 3-kinase-Akt/PKB survival pathway. Anticancer Drugs. 2003; 14:167-173. [PubMed: 12569304] 
[70]. Hideshima T, Catley L, Yasui H, et al. Perifosine, an oral bioactive novel alkylphospholipid, inhibits Akt and induces in vitro and in vivo cytotoxicity in human multiple myeloma cells. Blood. 2006; 107:4053-4062. [PubMed: 16418332]

[71]. Gills JJ, Dennis PA. Perifosine: update on a novel Akt inhibitor. Curr Oncol Rep. 2009; 11:102110. [PubMed: 19216841]

[72]. Ramakrishnan V, Kimlinger T, Haug J, et al. Anti-myeloma activity of Akt inhibition is linked to the activation status of PI3K/Akt and MEK/ERK pathway. PloS one. 2012; 7:e50005. [PubMed: 23185517]

[73]. Mounir Z, Krishnamoorthy JL, Wang S, et al. Akt determines cell fate through inhibition of the PERK-eIF2alpha phosphorylation pathway. Sci Signal. 2011; 4:ra62. [PubMed: 21954288]

[74]. Spencer A, Yoon SS, Harrison SJ, et al. The novel AKT inhibitor afuresertib shows favorable safety, pharmacokinetics, and clinical activity in multiple myeloma. Blood. 2014; 124:2190_ 2195. [PubMed: 25075128]

[75]. Cao H, Zhu K, Qiu L, et al. Critical role of AKT protein in myeloma-induced osteoclast formation and osteolysis. J Biol Chem. 2013; 288:30399-30410. [PubMed: 24005670]

[76]. Ikeda H, Hideshima T, Fulciniti M, et al. PI3K/p110\{delta\} is a novel therapeutic target in multiple myeloma. Blood. 2010; 116:1460-1468. [PubMed: 20505158]

[77]. O'Reilly KE, Rojo F, She QB, et al. mTOR inhibition induces upstream receptor tyrosine kinase signaling and activates Akt. Cancer Res. 2006; 66:1500-1508. [PubMed: 16452206]

[78]. Maiso P, Liu Y, Morgan B, et al. Defining the role of TORC1/2 in multiple myeloma. Blood. 2011; 118:6860-6870. [PubMed: 22045983]

[79]. Stengel C, Cheung CW, Quinn J, Yong K, Khwaja A. Optimal induction of myeloma cell death requires dual blockade of phosphoinositide 3-kinase and mTOR signalling and is determined by translocation subtype. Leukemia. 2012; 26:1761-1770. [PubMed: 22415553]

[80]. Cirstea D, Santo L, Hideshima T, et al. Delineating the mTOR kinase pathway using a dual TORC1/2 inhibitor, AZD8055, in multiple myeloma. Mol Cancer Ther. 2014; 13:2489-2500. [PubMed: 25172964]

[81]. Morgan GJ, Walker BA, Davies FE. The genetic architecture of multiple myeloma. Nat Rev Cancer. 2012; 12:335-348. [PubMed: 22495321]

[82]. Chang-Yew Leow C, Gerondakis S, Spencer A. MEK inhibitors as a chemotherapeutic intervention in multiple myeloma. Blood Cancer J. 2013; 3:e105. [PubMed: 23524590]

[83]. Steinbrunn T, Stuhmer T, Sayehli C, Chatterjee M, Einsele H, Bargou RC. Combined targeting of MEK/MAPK and PI3K/Akt signalling in multiple myeloma. Br J Haematol. 2012; 159:430-440. [PubMed: 22985491]

[84]. Chinen Y, Kuroda J, Shimura Y, et al. Phosphoinositide Protein Kinase PDPK1 Is a Crucial Cell Signaling Mediator in Multiple Myeloma. Cancer Res. 2014; 74:7418-7429. [PubMed: 25269480]

[85]. Gilmore TD. Multiple myeloma: lusting for NF-kappaB. Cancer Cell. 2007; 12:95-97. [PubMed: 17692798]

[86]. Hideshima T, Ikeda H, Chauhan D, et al. Bortezomib induces canonical nuclear factor-kappaB activation in multiple myeloma cells. Blood. 2009; 114:1046-1052. [PubMed: 19436050]

[87]. Fabre C, Mimura N, Bobb K, et al. Dual inhibition of canonical and noncanonical NF-kappaB pathways demonstrates significant antitumor activities in multiple myeloma. Clin Cancer Res. 2012; 18:4669-4681. [PubMed: 22806876]

[88]. Chapman MA, Lawrence MS, Keats JJ, et al. Initial genome sequencing and analysis of multiple myeloma. Nature. 2011; 471:467-472. [PubMed: 21430775]

[89]. Dimopoulos K, Gimsing P, Gronbaek K. The role of epigenetics in the biology of multiple myeloma. Blood Cancer J. 2014; 4:e207. [PubMed: 24786391]

[90]. Smith EM, Boyd K, Davies FE. The potential role of epigenetic therapy in multiple myeloma. Br J Haematol. 2010; 148:702-713. [PubMed: 19912222]

[91]. Kaiser MF, Johnson DC, Wu P, et al. Global methylation analysis identifies prognostically important epigenetically inactivated tumor suppressor genes in multiple myeloma. Blood. 2013; 122:219-226. [PubMed: 23699600] 
[92]. Walker BA, Wardell CP, Chiecchio L, et al. Aberrant global methylation patterns affect the molecular pathogenesis and prognosis of multiple myeloma. Blood. 2011; 117:553-562. [PubMed: 20944071]

[93]. Kouzarides T. Chromatin modifications and their function. Cell. 2007; 128:693-705. [PubMed: 17320507]

[94]. Lane AA, Chabner BA. Histone deacetylase inhibitors in cancer therapy. J Clin Oncol. 2009; 27:5459-5468. [PubMed: 19826124]

[95]. Minucci S, Pelicci PG. Histone deacetylase inhibitors and the promise of epigenetic (and more) treatments for cancer. Nat Rev Cancer. 2006; 6:38-51. [PubMed: 16397526]

[96]. Choudhary C, Kumar C, Gnad F, et al. Lysine acetylation targets protein complexes and coregulates major cellular functions. Science. 2009; 325:834-840. [PubMed: 19608861]

[97]. Hideshima T, Anderson KC. Histone deacetylase inhibitors in the treatment for multiple myeloma. Int J Hematol. 2013; 97:324-332. [PubMed: 23475757]

[98]. Mitsiades CS, Mitsiades NS, McMullan CJ, et al. Transcriptional signature of histone deacetylase inhibition in multiple myeloma: biological and clinical implications. Proc Natl Acad Sci U S A. 2004; 101:540-545. [PubMed: 14695887]

[99]. Catley L, Weisberg E, Tai YT, et al. NVP-LAQ824 is a potent novel histone deacetylase inhibitor with significant activity against multiple myeloma. Blood. 2003; 102:2615-2622. [PubMed: 12816865]

[100]. Catley L, Weisberg E, Kiziltepe T, et al. Aggresome induction by proteasome inhibitor bortezomib and alpha-tubulin hyperacetylation by tubulin deacetylase (TDAC) inhibitor LBH589 are synergistic in myeloma cells. Blood. 2006; 108:3441-3449. [PubMed: 16728695]

[101]. Maiso P, Carvajal-Vergara X, Ocio EM, et al. The histone deacetylase inhibitor LBH589 is a potent antimyeloma agent that overcomes drug resistance. Cancer Res. 2006; 66:5781-5789. [PubMed: 16740717]

[102]. Feng R, Oton A, Mapara MY, Anderson G, Belani C, Lentzsch S. The histone deacetylase inhibitor, PXD101, potentiates bortezomib-induced anti-multiple myeloma effect by induction of oxidative stress and DNA damage. Br J Haematol. 2007; 139:385-397. [PubMed: 17910628]

[103]. Khan SB, Maududi T, Barton K, Ayers J, Alkan S. Analysis of histone deacetylase inhibitor, depsipeptide (FR901228), effect on multiple myeloma. Br J Haematol. 2004; 125:156-161. [PubMed: 15059137]

[104]. Dimopoulos M, Siegel DS, Lonial S, et al. Vorinostat or placebo in combination with bortezomib in patients with multiple myeloma (VANTAGE 088): a multicentre, randomised, double-blind study. Lancet Oncol. 2013; 14:1129-1140. [PubMed: 24055414]

[105]. Richardson PG, Hungria VTM, Yoon S-S, et al. Panorama 1: A randomized, double-blind, phase 3 study of panobinostat or placebo plus bortezomib and dexamethasone in relapsed or relapsed and refractory multiple myeloma. ASCO Meeting Abstracts. 2014; 32:8510.

[106]. Hideshima T, Bradner JE, Wong J, et al. Small-molecule inhibition of proteasome and aggresome function induces synergistic antitumor activity in multiple myeloma. Proc Natl Acad Sci U S A. 2005; 102:8567-8572. [PubMed: 15937109]

[107]. Santo L, Hideshima T, Kung AL, et al. Preclinical activity, pharmacodynamic, and pharmacokinetic properties of a selective HDAC6 inhibitor, ACY-1215, in combination with bortezomib in multiple myeloma. Blood. 2012; 119:2579-2589. [PubMed: 22262760]

[108]. Quayle SN, Jones SS. ACY-1215, a First-In-Class Selective Inhibitor Of HDAC6, Demonstrates Significant Synergy With Immunomodulatory Drugs (IMiDs) In Preclinical Models Of Multiple Myeloma (MM). Blood. 2013; 122:1952. ASH meeting abstract.

[109]. Vogl DT, Raje N, Hari P, et al. Phase 1B Results of Ricolinostat (ACY-1215) Combination Therapy with Bortezomib and Dexamethasone in Patients with Relapsed or Relapsed and Refractory Multiple Myeloma (MM). Blood. 2014; 124:4764. ASH meeting abstract.

[110]. Yee AJ, Voorhees PM, Bensinger W, et al. Ricolinostat (ACY-1215), a Selective HDAC6 Inhibitor, in Combination with Lenalidomide and Dexamethasone: Results of a Phase $1 \mathrm{~b}$ Trial in Relapsed and Relapsed Refractory Multiple Myeloma. Blood. 2014; 124:4772. ASH meeting abstract. 
[111]. Hideshima T, Mazitschek R, Santo L, et al. Induction of differential apoptotic pathways in multiple myeloma cells by class-selective histone deacetylase inhibitors. Leukemia. 2014; 28:457-460. [PubMed: 24150220]

[112]. Minami J, Suzuki R, Mazitschek R, et al. Histone deacetylase 3 as a novel therapeutic target in multiple myeloma. Leukemia. 2014; 28:680-689. [PubMed: 23913134]

[113]. Wagner EJ, Carpenter PB. Understanding the language of Lys36 methylation at histone H3. Nat Rev Mol Cell Biol. 2012; 13:115-126. [PubMed: 22266761]

[114]. Martinez-Garcia E, Popovic R, Min DJ, et al. The MMSET histone methyl transferase switches global histone methylation and alters gene expression in $\mathrm{t}(4 ; 14)$ multiple myeloma cells. Blood. 2011; 117:211-220. [PubMed: 20974671]

[115]. Min DJ, Ezponda T, Kim MK, et al. MMSET stimulates myeloma cell growth through microRNA-mediated modulation of c-MYC. Leukemia. 2013; 27:686-694. [PubMed: 22972034]

[116]. Chase A, Cross NC. Aberrations of EZH2 in cancer. Clin Cancer Res. 2011; 17:2613-2618. [PubMed: 21367748]

[117]. Kalushkova A, Fryknas M, Lemaire M, et al. Polycomb target genes are silenced in multiple myeloma. PloS one. 2010; 5:e11483. [PubMed: 20634887]

[118]. Croonquist PA, Van Ness B. The polycomb group protein enhancer of zeste homolog 2 (EZH 2) is an oncogene that influences myeloma cell growth and the mutant ras phenotype. Oncogene. 2005; 24:6269-6280. [PubMed: 16007202]

[119]. van Haaften G, Dalgliesh GL, Davies H, et al. Somatic mutations of the histone H3K27 demethylase gene UTX in human cancer. Nat Genet. 2009; 41:521-523. [PubMed: 19330029]

[120]. Rizq O, Mimura N, Koide S, et al. EZH2 Inhibition and the Combination with Proteasome Inhibition Are Novel Potential Strategies for the Treatment of Multiple Myeloma. Blood. 2014; 124:2094. ASH meeting abstract. [PubMed: 24948658]

[121]. Croce CM. Causes and consequences of microRNA dysregulation in cancer. Nat Rev Genet. 2009; 10:704-714. [PubMed: 19763153]

[122]. Dimopoulos K, Gimsing P, Gronbaek K. Aberrant microRNA expression in multiple myeloma. Eur J Haematol. 2013; 91:95-105. [PubMed: 23586898]

[123]. Amodio N, Leotta M, Bellizzi D, et al. DNA-demethylating and anti-tumor activity of synthetic miR-29b mimics in multiple myeloma. Oncotarget. 2012; 3:1246-1258. [PubMed: 23100393]

[124]. Di Martino MT, Leone E, Amodio N, et al. Synthetic miR-34a mimics as a novel therapeutic agent for multiple myeloma: in vitro and in vivo evidence. Clin Cancer Res. 2012; 18:62606270. [PubMed: 23035210]

[125]. Ahmad N, Haider S, Jagannathan S, Anaissie E, Driscoll JJ. MicroRNA theragnostics for the clinical management of multiple myeloma. Leukemia. 2014; 28:732-738. [PubMed: 24714346]

[126]. Filippakopoulos P, Knapp S. The bromodomain interaction module. FEBS Lett. 2012; 586:2692-2704. [PubMed: 22710155]

[127]. Filippakopoulos P, Qi J, Picaud S, et al. Selective inhibition of BET bromodomains. Nature. 2010; 468:1067-1073. [PubMed: 20871596]

[128]. Delmore JE, Issa GC, Lemieux ME, et al. BET bromodomain inhibition as a therapeutic strategy to target c-Myc. Cell. 2011; 146:904-917. [PubMed: 21889194]

[129]. Pratt G, Goodyear O, Moss P. Immunodeficiency and immunotherapy in multiple myeloma. $\mathrm{Br}$ J Haematol. 2007; 138:563-579. [PubMed: 17686051]

[130]. Bensinger W. Allogeneic stem cell transplantation for multiple myeloma. Hematol Oncol Clin North Am. 2014; 28:891-902. [PubMed: 25212888]

[131]. Lu G, Middleton RE, Sun H, et al. The myeloma drug lenalidomide promotes the cereblondependent destruction of Ikaros proteins. Science. 2014; 343:305-309. [PubMed: 24292623]

[132]. Anderson KC. Lenalidomide and thalidomide: mechanisms of action--similarities and differences. Semin Hematol. 2005; 42:S3-8. [PubMed: 16344099]

[133]. Quach H, Ritchie D, Stewart AK, et al. Mechanism of action of immunomodulatory drugs (IMiDS) in multiple myeloma. Leukemia. 2010; 24:22-32. [PubMed: 19907437] 
[134]. Gorgun G, Calabrese E, Soydan E, et al. Immunomodulatory effects of lenalidomide and pomalidomide on interaction of tumor and bone marrow accessory cells in multiple myeloma. Blood. 2010; 116:3227-3237. [PubMed: 20651070]

[135]. Okazaki T, Chikuma S, Iwai Y, Fagarasan S, Honjo T. A rheostat for immune responses: the unique properties of PD-1 and their advantages for clinical application. Nat Immunol. 2013; 14:1212-1218. [PubMed: 24240160]

[136]. Pardoll DM. The blockade of immune checkpoints in cancer immunotherapy. Nat Rev Cancer. 2012; 12:252-264. [PubMed: 22437870]

[137]. Brahmer JR, Tykodi SS, Chow LQ, et al. Safety and activity of anti-PD-L1 antibody in patients with advanced cancer. N Engl J Med. 2012; 366:2455-2465. [PubMed: 22658128]

[138]. Topalian SL, Hodi FS, Brahmer JR, et al. Safety, activity, and immune correlates of anti-PD-1 antibody in cancer. N Engl J Med. 2012; 366:2443-2454. [PubMed: 22658127]

[139]. Hamid O, Robert C, Daud A, et al. Safety and tumor responses with lambrolizumab (anti-PD-1) in melanoma. N Engl J Med. 2013; 369:134-144. [PubMed: 23724846]

[140]. Ansell SM, Lesokhin AM, Borrello I, et al. PD-1 blockade with nivolumab in relapsed or refractory Hodgkin's lymphoma. N Engl J Med. 2015; 372:311-319. [PubMed: 25482239]

[141]. Liu J, Hamrouni A, Wolowiec D, et al. Plasma cells from multiple myeloma patients express B7-H1 (PD-L1) and increase expression after stimulation with IFN-\{gamma $\}$ and TLR ligands via a MyD88-, TRAF6-, and MEK-dependent pathway. Blood. 2007; 110:296-304. [PubMed: 17363736]

[142]. Tamura H, Ishibashi M, Yamashita T, et al. Marrow stromal cells induce B7-H1 expression on myeloma cells, generating aggressive characteristics in multiple myeloma. Leukemia. 2013; 27:464-472. [PubMed: 22828443]

[143]. Benson DM Jr. Bakan CE, Mishra A, et al. The PD-1/PD-L1 axis modulates the natural killer cell versus multiple myeloma effect: a therapeutic target for CT-011, a novel monoclonal antiPD-1 antibody. Blood. 2010; 116:2286-2294. [PubMed: 20460501]

[144]. Rosenblatt J, Glotzbecker B, Mills H, et al. PD-1 blockade by CT-011, anti-PD-1 antibody, enhances ex vivo T-cell responses to autologous dendritic cell/myeloma fusion vaccine. $\mathrm{J}$ Immunother. 2011; 34:409-418. [PubMed: 21577144]

[145]. Iwai Y, Ishida M, Tanaka Y, Okazaki T, Honjo T, Minato N. Involvement of PD-L1 on tumor cells in the escape from host immune system and tumor immunotherapy by PD-L1 blockade. Proc Natl Acad Sci U S A. 2002; 99:12293-12297. [PubMed: 12218188]

[146]. Kearl TJ, Jing W, Gershan JA, Johnson BD. Programmed death receptor-1/programmed death receptor ligand-1 blockade after transient lymphodepletion to treat myeloma. J Immunol. 2013; 190:5620-5628. [PubMed: 23616570]

[147]. Hallett WH, Jing W, Drobyski WR, Johnson BD. Immunosuppressive effects of multiple myeloma are overcome by PD-L1 blockade. Biol Blood Marrow Transplant. 2011; 17:11331145. [PubMed: 21536144]

[148]. Atanackovic D, Luetkens T, Kroger N. Coinhibitory molecule PD-1 as a potential target for the immunotherapy of multiple myeloma. Leukemia. 2014; 28:993-1000. [PubMed: 24153012]

[149]. Gabrilovich DI, Nagaraj S. Myeloid-derived suppressor cells as regulators of the immune system. Nat Rev Immunol. 2009; 9:162-174. [PubMed: 19197294]

[150]. Gabrilovich DI, Ostrand-Rosenberg S, Bronte V. Coordinated regulation of myeloid cells by tumours. Nat Rev Immunol. 2012; 12:253-268. [PubMed: 22437938]

[151]. Gorgun GT, Whitehill G, Anderson JL, et al. Tumor-promoting immune-suppressive myeloidderived suppressor cells in the multiple myeloma microenvironment in humans. Blood. 2013; 121:2975-2987. [PubMed: 23321256]

[152]. Ramachandran IR, Martner A, Pisklakova A, et al. Myeloid-derived suppressor cells regulate growth of multiple myeloma by inhibiting T cells in bone marrow. J Immunol. 2013; 190:38153823. [PubMed: 23460744]

[153]. Serafini P, Meckel K, Kelso M, et al. Phosphodiesterase-5 inhibition augments endogenous antitumor immunity by reducing myeloid-derived suppressor cell function. J Exp Med. 2006; 203:2691-2702. [PubMed: 17101732] 
[154]. Noonan KA, Ghosh N, Rudraraju L, Bui M, Borrello I. Targeting immune suppression with PDE5 inhibition in end-stage multiple myeloma. Cancer Immunol Res. 2014; 2:725-731.

[PubMed: 24878583] 


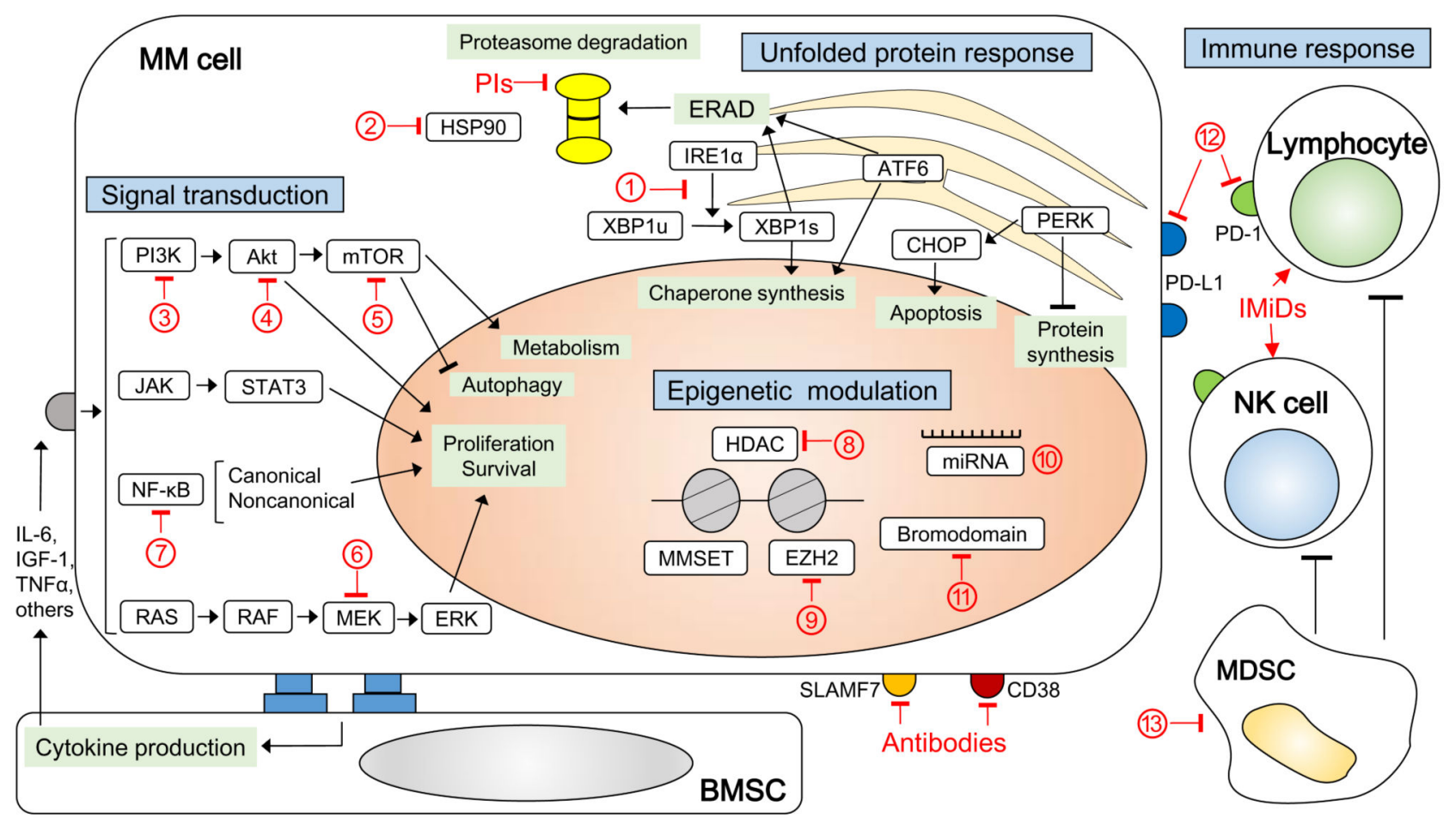

Figure 1. The overview of novel therapeutic approaches for multiple myeloma (MM)

The scheme of novel therapeutic targets and treatment options (\#1-13) discussed in this review article are highlighted. The specific treatment options and representative drugs are also shown below.

1: IRE1a inhibitors (MKC-3946 [42], STF-083010 [45]), 2: HSP90 inhibitors (17-AAG, TAS-116 [30]), 3: PI3K inhibitors (CAL-101 [76]), 4: Akt inhibitors (perifosine, afuresertib [74], TAS-117 [23], MK-2206 [72]), 5: mTOR inhibitors (rapamycin, everolimus, temsirolimus), 6: MEK inhibitors (selumetinib), 7: NF- $\kappa \mathrm{B}$ inhibitors (PBS-1086 [87]), 8: HDAC inhibitors (vorinostat, panobinostat, ricolinostat [107], BG45 [112]), 9: EZH2 inhibitors (UNC1999 [120]), 10: synthetic miRNAs (miR-29b [123], miR-34a [124]), 11: Bromodomain inhibitors (JQ1 [128]), 12: PD-1/PD-L1 antibodies (CT-011 [143]), 13: PDE5 inhibitors PIs (proteasome inhibitors): bortezomib, carfilzomib, ixazomib, marizomib IMiDs (immunomodulatory drugs): thalidomide, lenalidomide, pomalidomide Anti-SLAMF7 antibody: elotuzumab Anti-CD38 antibody: daratumumab 